\title{
The Bristol Registry of Bone Dysplasias: the first 10 years
}

\author{
I R S GORDON* AND T J DAVID
}

From the Department of Radiology, Bristol Children's Hospital, Bristol, and Department of Child Health, University of Manchester, Manchester

SUMmaRY The Bristol Bone Dysplasia Registry was established in 1969. The panel included radiologists, paediatricians, orthopaedic surgeons, pathologists, a paediatric biochemist, an anatomist/anthropologist, a veterinary surgeon, dentists and oral surgeons, and a psychiatrist. The panel met every two months.

Cases either entered the Registry directly if they were straightforward or after discussion by the panel if there was doubt about the diagnosis or a point of special interest. A total of 468 cases was collected, including 81 cases with miscellaneous bony disorders and 34 cases where the diagnosis was uncertain.

The Registry provided a useful regional diagnostic service and promoted interest in bone dysplasias. Some of the research aims have not yet been fully achieved.

This paper explains how the Registry is run to help those whom it is hoped will set up similar registries elsewhere.

In the past 20 years, there has been increasing interest in bone dysplasias. This is reflected in the number of recent new books largely or entirely devoted to the subject. ${ }^{1-9}$ It has been recognised that this group of disorders comprises numerous distinct entities, the classification of these disorders being based primarily on the radiographic appearances.

The rapid evolution in the recognition and delineation of bone dysplasias led to a good deal of confusion when attempts were made to classify these disorders. In 1969, at the initiative of the European Society for Paediatric Radiology, a group of specialists met in Paris and produced a classification for bone dysplasias. ${ }^{10}$ This has been revised recently. ${ }^{11}$

In 1969 it was decided to set up a registry in Bristol for recording information about cases of bone dysplasia. This was set against the background in Bristol of a well established Bone Tumour Registry and also a Bladder Tumour Registry (the latter is now disbanded). The project was initiated because of the difficulty experienced by people interested in the field in gaining experience of the different types of bone dysplasia. Cases of bone dysplasia are all relatively uncommon and many so rare that it is

*Dr Gordon died suddenly in early 1979. The working of the Registry is continuing.

Received for publication 12 July 1980 unlikely that one person will meet with more than one or two examples during his professional career. Furthermore, some of the conditions included in this group are still not very clearly defined entities and are often genetically or biochemically heterogeneous and of uncertain aetiology and pathogenesis, adding to the difficulty of recognition. The establishment of bone dysplasia registries such as those of Maroteaux in France and Spranger in Germany has facilitated the accumulation of material and the delineation of many of these conditions.

The purpose of this paper is to explain how the Registry is run, the aim being to help those whom it is hoped will set up similar registries elsewhere. Specially included is a list of cases in the Registry, partly to give an idea of the kind of material to be expected when setting up a registry, but also because the material remains available for further study.

\section{Constitution of the panel}

The intention was to have a panel consisting of members with expertise in a wide variety of fields. The composition of the panel has changed slightly over the years but consisted of:

Chairman: Professor N R Butler, Professor of Child Health, University of Bristol 
Secretary: Dr I R S Gordon, Consultant Radiologist

Radiologists

Paediatricians (including those with a special interest in genetics)

Orthopaedic surgeons

Members of the University dental staff (with special interest in orthodontics, oral pathology, and oral surgery)

A psychiatrist (with special interest in mental subnormality)

Paediatric and general pathologists

A paediatric biochemist

An anatomist (anthropologist)

A member of the University Veterinary School with special interest in skeletal dysplasias.

A bone dysplasia panel would normally include a clinical geneticist, but the south-west region does not have one. However, the panel included two paediatricians with a major interest in genetics, one of whom does genetic counselling. In addition, two frequent guests were full-time clinical geneticists from other regions.

\section{Organisation}

The Registry has been organised with a permanent chairman and secretary from among the panel members. Financial resources have not permitted any very elaborate or sophisticated system of record keeping, but a part-time lay secretary has been appointed and a small office provided by the University Department of Child Health and the Bristol Royal Hospital for Sick Children. The scheme is at present financed by the South West Regional Health Authority Research Committee.

\section{Meetings}

Ordinary meetings of the Registry are held in the evening once every two months and are attended by most of the panel members and by a number of interested guests. These meetings involve the consideration of two or three cases referred by colleagues working in the south-west and on occasion from outside the region. Short notes on these cases are circulated to panel members before the meeting.

The clinician referring the patient usually gives a summary of the case history and results of any relevant investigations. Radiographs are shown and, where possible, the biochemical, histological, oral, and dental findings are presented together with the dermatoglyphs.

Discussion of the various features, useful further investigations, prognosis, and treatment of the case then follows and, if possible, it is allocated a place in the classification.

As a rule patients were not seen. However, on a few occasions where it was convenient the clinician brought the patient to a meeting.

Meetings sometimes also included a 20-minute paper on some aspect of bone dysplasias, either by one of the panel members or by an invited speaker from outside. Table 1 lists the papers that have been given. From time to time special meetings have been arranged jointly with other similar organisations, especially the South Wales Bone Dysplasia group with which there is close liaison, assisted by some degree of joint membership and the geographical proximity of the two groups. In 1976 a 2-day Symposium on Bone Dysplasias was arranged to which speakers from other centres in the United Kingdom and overseas contributed. This venture was considered to be successful in achieving its aims of spreading interest in the skeletal dysplasias and its proceedings were published. ${ }^{12}$

\section{Registration}

The Registry has adopted the classification of the Nomenclature for Constitutional Bone Disease which has been recently revised. ${ }^{11}$

Cases either entered the Registry directly if they were straightforward, or after discussion by the panel if there was doubt about the diagnosis or some point of special interest.

The Registry has accumulated the following cases: (1) 353 cases classified according to the International Nomenclature;

(2) 34 cases where the diagnosis was uncertain; and

(3) 81 cases not included in the International Nomenclature.

The cases are listed in tables 2 and 3.

\section{TABLE 1 List of papers presented at meetings of the} panel

(1) Achondrogenesis and other forms of micromelic dwarfism.

(2) Histology of achondrogenesis.

(3) Recent experimental work on osteopetrosis in the mouse.

(4) Brachydactyly -33 cases reviewed.

(5) Autosomal dominant hip dysplasia.

(6) Pelvis and hips in Down's syndrome.

(7) Defects of the cranial vault

(8) Dental malocclusion and jaw abnormalities in craniostenosis.

(9) Biochemical aspects of sclerosing dysplasias.

(10) A non-radiological method of demonstrating skeletal structures in stillborn fetuses.*

(11) Histopathology in relation to bone dysplasias.

(12) Dental aspects of bone dysplasias.

(13) Applications of orthopaedic surgery to bone dysplasias.

(14) Application of medical genetics to bone dysplasias.

(15) Orthopaedic problems relating to treatment of limb inequality.

(16) Craniostenosis-disabilities and treatment.

(17) Cephalometric parameters in hypopituitary patients. 
TABLE 2 Cases in the Bristol Bone Dysplasia Registry: 1969-1979

\section{Osteochondrodysplasias}

Abnormalities of cartilage and/or bone growth and development

I. DEFECTS OF GROWTH OF TUBULAR BONES AND/OR SPINE

(A) Identifiable at birth

(1) Achondrogenesis type I (Parenti-Fraccaro)

(2) Achondrogenesis type II (Langer-Saldino)

(3) Thanatophoric dysplasia

(5) Short rib-polydactyly syndrome type I

(7c) Chondrodysplasia punctata

(8) Campomelic dysplasia

(10) Achondroplasia

(11) Diastrophic dysplasia

(12) Metatropic dysplasia

(13) Chondroectodermal dysplasia (Ellis-van Creveld)

(14) Asphyxiating thoracic dysplasia (Jeune)

(15b) Spondyloepiphyseal dysplasia congenita

(16) Kniest dysplasia

(17e) Mesomelic dysplasia

(19) Cleidocranial dysplasia

(B) Identifiable in later life

(1) Hypochondroplasia

(2) Dyschondrosteosis

(4) Metaphyseal chondrodysplasia type Schmid

(6) Metaphyseal chondrodysplasia with exocrine pancreatic insufficiency and cyclic neutropenia

(7b) Spondylometaphyseal dysplasia

(8b) Multiple epiphyseal dysplasia

(10) Pseudoachondroplasia

(11) Spondyloepiphyseal dysplasia tarda

(17) Trichorhinophalangeal dysplasia

II. DISORGANISED DEVELOPMENT OF CARTILAGE AND FIBROUS COMPONENTS OF SKELETON

(1) Dysplasia epiphysealis hemimelica

(2) Multiple cartilaginous exostoses

(4) Enchondromatosis (Ollier)

(7) Fibrous dysplasia (Jaffe-Lichtenstein)

(8) Fibrous dysplasia with skin pigmentation and precocious puberty (McCune-Albright)

(9) Cherubism (familial fibrous dysplasia of the jaws)

III. ABNORMALITIES OF DENSITY OF CORTICAL DIAPHYSEAL STRUCTURE AND/OR METAPHYSEAL MODELLING

(1) Osteogenesis imperfecta congenita

(2) Osteogenesis imperfecta tarda

(5) Osteopetrosis with precocious manifestations

(6) Osteopetrosis with delayed manifestations

(8) Osteopoikilosis

(11) Diaphyseal dysplasia (Camurati-Engelmann)

(19) Metaphyseal dysplasia (Pyle)

(22) Osteoectasia with hyperphosphatasia

\section{Dysostoses}

Malformation of individual bones, singly or in combination

I. DYSOSTOSES WITH CRANIAL AND FACIAL INVOLVEMENT

(1) Craniosynostosis

(2) Craniofacial dysostosis (Crouzon)

(3) Acrocephalosyndactyly (Apert)

(4) Acrocephalopolysyndactyly (Carpenter)

(5b) Mandibulofacial dysostosis

(6) Oculomandibulofacial syndrome

II. DYSOSTOSES WITH PREDOMINANT AXIAL INVOLVEMENT

(1) Vertebral segmentation defects

(4) Spondylocostal dysostosis

(6) Osteoonychodysostosis

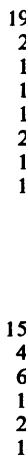

III. DYSOSTOSES WITH PREDOMINANT INVOLVEMENT OF EXTREMITIES

(2) Apodia

(7) Brachydactyly

(9) Polydactyly

(10) Syndactyly
(13) Poland syndrome

(14) Rubinstein-Taybi syndrome

(15) Pancytopenia-dysmelia syndrome (Fanconi)

(18) Cardiomelic syndrome

Idiopathic osteolyses

(2a) Tarsocarpal

Chromosomal aberrations

Primary metabolic abnormalities

I. CALCIUM AND/OR PHOSPHORUS

(1) Hypophosphataemic rickets

(5) Hypophosphatasia

II. COMPLEX CARBOHYDRATES

(1a) Mucopolysaccharidosis, type I (Hurler)

(1b) Mucopolysaccharidosis, type I (Scheie)

(2) Mucopolysaccharidosis, type II (Hunter)

(3) Mucopolysaccharidosis, type III (San Filippo)

(4) Mucopolysaccharidosis, type IV (Morquio)

(13) Mucolipidosis II

AMINO-ACIDS

(1) Homocystinuria/phenylketonuria

Total cases tabulated

353

The figures in brackets are cases referred from the Bristol Bone Tumour Registry who hold the clinical, radiological, and histological records.

TABLE 3 Miscellaneous disorders, not included in the International Nomenclature, included in the Bristol Bone Dysplasia Registry

(1) Dysostosis with cranial involvement

(2) Dysostosis with metaphyseal involvement

(3) Dysostosis with peripheral involvement

(4) Facial chondrodysplasia

(5) Acroepiphyseometaphyseal dysplasia (Brailsford)

(6) Arthrogryposis multiplex

(7) Infantile pseudarthrosis

(8) Talar enarthrosis

(9) Laurence-Moon-Biedl syndrome

(10) Macrodactyly

(1) (11) Abnormalities of cortical density

(12) Amelia

(1) (13) Dysmelia

(14) Hemimelia

(16) Sacral agenesis

(17) Body asymmetry

(1i) Thalidomide embryopathy

(19) Oncogenic rickets

(20) Anticonvulsant rickets

(21) Skeletal hypoplasia associated with vascular soft tissue tumour

(22) Seckel bird-headed dwarfism

(23) Russell-Silver dwarfism

(24) Short stature

(25) Cebocephaly

(26) Meningocele with iniencephaly

(27) Popliteal pterygium syndrome

(28) Hand-Schuller-Christian disease

(29) Marfan syndrome

(30) Ehlers-Danlos syndrome II

(31) Pseudopseudohypoparathyroidism

(32) Smith-Lemli-Opitz syndrome

(33) Ullrich's syndrome (1 male, 1 female)

(34) Generalised gangliosidosis

(35) Patient registered but diagnosis uncertain 
A total of 139 cases had been discussed by the panel and the rest entered the Registry without discussion.

\section{Functions and evolution of the Registry}

\section{EDUCATIONAL}

There seems little doubt as far as individual members of the panel are concerned, particularly those most closely concerned in the organisation of the meetings and the running of the Registry generally, that its existence has stimulated their interest in the subject. Their knowledge of the diagnostic aspects of this group of diseases has become more complete, even if, as yet, it amounts in the case of some conditions to little more than a recognition of ignorance.

\section{DIAGNOSTIC}

The number of cases referred increased as knowledge of the aims and existence of the Registry became more widely known. As part of the Registry's function, a diagnostic service has been provided for Bristol and the south-west region.

\section{RESEARCH}

For each recognised clinical condition case material is being accumulated which can be used as a source for further investigation or as a standard with which new cases can be compared. Where possible, pathological material, such as tissues removed at operation, teeth, fibroblasts, blood, and urine, is being preserved for future histological and biochemical use.

There are, of course, major difficulties inherent in a study of the histopathology and histochemistry of this group of diseases, not least the lack of biopsy or necropsy material and the varying nature of the pathological changes involved.

\section{Problems and discussion}

\section{DATA RECORDING}

Information about patients is recorded by the clinician on a lengthy four page pro-forma. Completion of these forms was often incomplete, partly because some of the clinical data requested were not available. There is debate about whether a shorter form might be preferable, making the handling of data simpler, but the view was that such data as were available should be recorded.

A follow-up form was sent to the referring clinician or the GP or both about 2 years after the initial referral. This sought information about any clinical change and about any further investigations on other affected family members.
Data were transferred to a seven-page form and were coded so as to be suitable for card punching and computer storage. The key was held by a clinician.

\section{ETHICS}

Patients were not informed by the Registry that they had been registered, the decision about this being left to referring physicians. In the cases in which we personally came into contact with the families, the gratitude of the patients for attaching a particular diagnostic label was often out of all proportion to the possible benefits this entailed. As Asher ${ }^{13}$ wrote: "However uninformative the name of his illness may be, a patient feels his foe is partly vanquished once he knows its name".

Access to the material of the Registry was through the Secretary but it was understood that direct access to the patient or his family could only be made with permission of the referring physician and the general practitioner.

\section{AGE OF CASES}

There was a strong paediatric bias in the material collected. No adult physician was on the panel. It is likely that if there had been a full-time clinical geneticist in the region then more adult cases would have been referred to the Registry. There was also a lack of fetal material, although one of us developed a non-radiological technique for studying the skeleton of fetuses (see page 262).

\section{USE OF THE MATERIAL FOR RESEARCH}

In general, the aim to collect biochemical material for future study did not succeed. Further, relatively little research was done on the collected material which remains available.

\section{DENTAL ASPECTS}

It is becoming clear that the dental and oral manifestations of many bone dysplasias are as distinctive as the other clinical features and a registry without strong dental support would be incomplete.

The teeth are unlike any other organs in the body in that they retain in their ectodermal or mesodermal components evidence of disturbances in pre- and postnatal development which can be demonstrated many years later. The record is sometimes observable clinically but may require special histological investigation of extracted or shed teeth. Unfortunately, the lack of accurate information about the dental status in many case reports has reduced their potential value. The incidence of dental defects and errors of eruption in bone dysplasias is inadequately documented and thus the diagnostic 
value of the dentition as an aid to determining the time of onset or the type of dysplasia needs further investigation.

Just as scarce in published reports are records of measurements of the craniofacial dimension of patients with bone dysplasias. Many potentially useful linear and angular measurements can be obtained from cephalometric radiographs, ${ }^{14}$ and the introduction of three dimensional skull measurements might increase the value of this type of examination. Craniofacial abnormalities in bone dysplasias need accurate recording if their diagnostic value is to be properly assessed and used.

\section{DERMATOGLYPHS}

Unfortunately dermatoglyphs were not recorded in all cases. However, they were found to be of specific interest in detecting syndactyly and symphalangism, possibly in dating the onset of the dysplasia, in studying asymmetry in dysplasias, and very rarely in providing specific diagnostic features. ${ }^{15}$

\section{CLINICAL SERVICE AND GENETIC \\ COUNSELLING}

In bone dysplasias a firm diagnosis is essential for a meaningful prognosis and effective genetic counselling. ${ }^{16} 17$ The most useful result of the Registry was the provision of a diagnostic label to referring paediatricians and orthopaedic surgeons. Patient counselling was done by the referring clinician, although in recent years a counselling service for children of short stature because of bone dysplasia has developed, involving mainly an orthopaedic surgeon and a medical social worker.

Where specific genetic information was available this was also passed on to the referring doctor. Ideally, however, many of these patients would have been seen by a clinical geneticist. In theory any doctor should be able to ascertain a full family history. In practice, however, this may not happen, and frequently details of family history given to the Registry were brief and sketchy. Further, the person looking into the family history needs to be aware of minor forms of the disorder that may be present in relatives, for example the abnormal skull shape found in osteogenesis imperfecta.

\section{EPIDEMIOLOGY}

The material collected represents an unknown proportion of the total number of cases in the community, so that no data on disease incidence can be given. The classified cases do give some information about the relative frequency of the disorders listed, with any bias probably favouring the very rare and bizarre, since in these diagnostic assistance was often sought.
SCOPE OF THE REGISTRY

Material included was not confined to conditions listed in the International Nomenclature and table $\overline{0}$ 3 reflects the broad interests of the Registry. It is not $\frac{\bar{\sigma}}{\mathrm{c}}$ easy to define precisely what is or what is not a bone $\overline{\bar{\sigma}}$. dysplasia and these difficulties are exemplified by conditions such as Perthes disease. ${ }^{18}$

\section{Conclusion}

Not all the aims of the Registry have been fully $\vec{\omega}$ realised yet. However, a useful clinical service has been provided and much local interest has been $\stackrel{0}{0}$ stimulated. Full research use of the material collected $\vec{\infty}$ is awaited. The Registry will continue to furction, and is prepared to receive material from both inside $N$ and outside the south-west region, although it is hoped that this paper will stimulate those in other $\triangle$ regions to establish registries of their own.

We are indebted to the members of the panel for $\frac{c}{\omega}$ their comments and help in preparing the manu- $\overrightarrow{\mathscr{\theta}}$ script, particularly Dr C H G Price, Professor N R Butler, and Mr J P Fletcher, and to Mrs V E Green . for typing the manuscript.

\section{References}

1 Bergsma D. The first conference on the clinical delineation of birth defects. Part IV. Skeletal dysplasias. Birth Defects: Original Article Series. vol 5, No 4. New York: The $\overline{\bar{D}}$ National Foundation-March of Dimes, 1969.

2 Bergsma D. Skeletal dysplasias. Birth Defects: Original $\underset{7}{ }$ Article Series. vol 10, No 9. New York: Stratton Intercontinental, 1974.

3 Bergsma D. Skeletal dysplasias. Birth Defects: Original Article Series. vol 10, No 12. Amsterdam: Elsevier, 1974.

4 Spranger JW, Langer LO, Wiedemann HR. Bone dys- 음 plasias. An atlas of constitutional disorders of skeletal 3 development. Philadelphia: Saunders, 1974.

5 Skeletal dysplasias. In: Clinical orthopaedics and related research. No 114. Philadelphia: Lippincott, 1976. J Med Genet 1980; 17: 416-23.

6 Wynne-Davies R, Fairbank TJ. Fairbank's atlas of general affection of the skeleton. 2nd ed. Edinburgh: $\frac{7}{2}$ Churchill Livingstone, 1976.

7 Beighton P. Inherited disorders of the skeleton. Edinburgh: N Churchill Livingstone, 1978.

8 Cremin BJ, Beighton P. Bone dysplasias of infancy. A N radiological atlas. Berlin: Springer-Verlag, 1978.

9 Maroteaux P. Bone diseases of children. Philadelphia: $\omega$ Lippincott, 1979.

10 McKusick VA, Scott CI. A nomenclature for constitutional disorders of bone. J Bone Joint Surg (Am) $1971 ; 53: \frac{C}{\mathbb{D}}$ 978-86.

11 Rimoin DL. International nomenclature of constitutional diseases of bone. Revision May 1977. Am J Med Genet 1979;3:21-6.

12 Price CHG, ed. Proceedings of a symposium held at the University of Bristol organised by the Bristol Registry of $\frac{O}{\Phi}$ Bone Dysplasias, 2 and 3 April 1976. Postgrad Med $J \stackrel{\mathbb{Q}}{\varrho}$ 1977;53:421-524. 
13 Jones FA. Richard Asher talking sense. London: Pitman, 1972.

14 Gordon IRS, Ross FGM. Diagnostic radiology in paediatrics. London: Butterworths, 1977.

15 David TJ. Dermatoglyphs in skeletal dysplasias. Postgrad Med J 1977;53:438-9.

16 Wynne-Davies R. Heritable disorders in orthopaedic practice. Oxford: Blackwell, 1973.
17 Carter CO, Fairbank TJ. The genetics of locomotor disorders. London: Oxford University Press, 1974.

18 Beighton P. Discussion. Postgrad Med J 1977;53:471.

Requests for reprints to Dr T J David, Booth Hall Children's Hospital, Charlestown Road, Blackley, Manchester M9 2AA. 